\title{
Conditional Ablation of Neuroprogenitor Cells in Adult Mice Impedes Recovery of Poststroke Cognitive Function and Reduces Synaptic Connectivity in the Perforant Pathway
}

\author{
Chongran Sun, ${ }^{1,2,3}$ Hui Sun, ${ }^{1,2,4}$ Steven Wu, ${ }^{1,2}$ Chih Cheng Lee, ${ }^{1,2}$ Yosuke Akamatsu, ${ }^{1,2,5}$ Ruikang K. Wang, ${ }^{6}$ \\ Steven G. Kernie, ${ }^{7}$ and Jialing Liu ${ }^{1,2}$ \\ ${ }^{1}$ Department of Neurological Surgery, University of California, San Francisco, San Francisco, California 94121, ${ }^{2}$ San Francisco VA Medical Center, San \\ Francisco, California 94121, ${ }^{3}$ Department of Neurological Surgery, Second Affiliated Hospital of Zhejiang University Medical College, Hangzhou 310009, \\ China, ${ }^{4}$ Department of Neurological Surgery, Xinhua Hospital, Shanghai Jiaotong University, Shanghai 201101, China, ${ }^{5}$ Department of Neurological \\ Surgery, Tohoku University Graduate School of Medicine, Aoba-ku, Sendai 980-8574, Japan, ${ }^{6}$ Departments of Bioengineering and Ophthalmology, \\ University of Washington, Seattle, Washington 98195, and 7 Departments of Pediatrics, Pathology and Cell Biology, Columbia University, New York, New \\ York 10032
}

The causal relationship between neurogenesis and the recovery of poststroke cognitive function has not been properly explored. The current study aimed to determine whether depleting neuroprogenitor cells (NPCs) affects poststroke functional outcome in nestin- $\delta$ HSV-TK-EGFP transgenic mice, in which the expression of a truncated viral thymidine kinase gene and EGFP was restricted to nestinexpressing NPCs. Ganciclovir (GCV; $200 \mathrm{mg} / \mathrm{kg} / \mathrm{d})$ or saline was continuously administered via osmotic pumps in mice for 4 weeks before the induction of experimental stroke. Both baseline and stroke-induced type 1 and type 2 NPCs were conditionally ablated. GCV eliminated NPCs in a duration-dependent fashion, but it did not attenuate the genesis of astroglia or oligodendrocytes in the peri-infarct cortex, nor did it affect infarct size or cerebral blood reperfusion after stroke. Transgenic stroke mice given GCV displayed impaired spatial learning and memory in the Barnes maze test compared with saline control or wild-type stroke mice given GCV, suggesting a contributing role of stroke-induced neurogenesis in the recovery of cognitive function. However, there was no significant difference in poststroke motor function between transgenic mice treated with GCV and those treated with vehicle, despite a significant ablation of NPCs in the subventricular zone of the former. Furthermore, nestin- $\delta$-HSV-TK-EGFP mice treated with GCV had fewer retrogradely labeled neurons in the entorhinal cortex (EC) when injected with the polysynaptic viral marker PRV614 in the dentate gyrus (DG), suggesting that there might be reduced synaptic connectivity between the DG and EC following ablation of NPCs, which may contribute to impaired poststroke memory function.

\section{Introduction}

Although motor impairment is well documented in patients who have suffered from ischemic stroke, the underlying mechanisms leading to cognitive impairments or cognitive recovery are less understood. Recent studies suggest that the prevalence of developing new dementia among first-ever stroke patients is $\sim 10 \%$, while the chance of developing delayed poststroke dementia is as high as 50\% among stroke survivors (Pendlebury and Rothwell, 2009a, b), indicating a clear need in finding effective therapeutic

\footnotetext{
Received May 17, 2013; revised Sept. 3, 2013; accepted Sept. 18, 2013.

Author contributions: J.L. designed research;C.S., H.S., S.W., C.C.L., Y.A., and J.L. performed research; R.K.W. and S.G.K. contributed unpublished reagents/analytic tools; C.S., H.S., C.C.L., Y.A., R.K.W., and J.L. analyzed data; C.S. and J.L. wrote the paper.

This work was supported by National Institutes of Health Grants R01 NS071050 (J.L.) and AHA EIA 0940065N (J.L.). We thank Dr. Lin An for his technical assistance in the analysis of blood perfusion by optical coherence tomography.

Correspondence should be addressed to Dr. Jialing Liu, Department of Neurological Surgery (112C), University of California, San Francisco, and Department of Veterans Affairs Medical Center, 4150 Clement Street, San Francisco, CA 94121. E-mail: jialing.liu@ucsf.edu.

DOI:10.1523/JNEUROSCI.2129-13.2013

Copyright $\odot 2013$ the authors $\quad 0270-6474 / 13 / 3317314-12 \$ 15.00 / 0$
}

intervention to promote the recovery of poststroke cognitive function.

Brain injury including stroke stimulates the production of new neurons in the adult brain from neuroprogenitor cells (NPCs) residing in the subventricular zone (SVZ) and the dentate gyrus (DG; Lichtenwalner and Parent, 2006, Kernie and Parent, 2010). While there is a strong association between poststroke functional recovery and neurogenesis, and a functional role for adult hippocampal neurogenesis in spatial learning and memory has been established in healthy subjects (Deng et al., 2010, Aimone et al., 2011), the contribution of neurogenesis to the recovery of cognitive function after ischemic brain injury has not been adequately addressed. Previous studies have used antimitotic agents (Arvidsson et al., 2002, Zhang et al., 2004) or ionized irradiation (Raber et al., 2004) to eliminate NPCs after brain ischemia, and the latter strategy also resulted in exacerbated functional impairment induced by brain ischemia. The caveats of these approaches include nonspecific elimination of dividing cells in lineages in addition to NPCs that might affect brain function, such as microglia, endothelial cells, or astroglia. In addition, 
these ablation techniques themselves can elicit an inflammatory response or potential toxicity. To circumvent earlier limitations, we generated a transgenic mouse line with modified herpes simplex virus (HSV)-thymidine kinase (TK) driven by the nestin promoter and its second intron regulatory element, which allowed for temporally regulated ablation of dividing neural progenitors by the administration of ganciclovir (Yu et al., 2008).

Cognitive impairment occurs not only in various domains after stroke in human patients, but also in experimental animals, as manifested by memory deficits. Exposure to an enriched environment not only enhanced hippocampal neurogenesis, but also attenuated memory impairment as well as hippocampal hypoactivation, induced by middle cerebral artery distal occlusion (Wang et al., 2011a). However, the causal relationship between hippocampal neurogenesis and the recovery of cognitive function remains to be established. NPCs were shown to secrete trophic factors that could potentially stabilize the neurovascular network, regulate vascular growth and blood flow, and provide neuroprotection (Rafuse et al., 2005). Consistent with the neuroprotective role of NPCs, targeted depletion of doublecortin (DCX)-expressing cells was linked to worsened stroke lesion size and motor impairment (Jin et al., 2010; Wang et al., 2012). However, the role of NPCs in poststroke cognitive function was never assessed. In the current study, we examined the causal relationship between neurogenesis and functional recovery following experimental stroke in the nestin- $\delta$-HSV-TK-EGFP transgenic mice. We also determined whether the conditional ablation of NPCs affected cerebral blood flow during the reperfusion phase following middle cerebral artery occlusion (MCAO) and how it affected synaptic connectivity in the perforant pathway during the recovery from chronic stroke.

\section{Materials and Methods \\ Animals}

Mice were bred and housed in accordance with the animal care guidelines issued by the National Institutes of Health and by the Institutional Animal Use and Care Committee. Nestin- $\delta$-HSV-TK-EGFP (referred as $\mathrm{TK}^{+}$), a transgenic mouse line containing a modified version of the HSV-TK ( $\delta$-HSV-TK) and IRES-EGFP, driven by the nestin promoter and its second intron regulatory element, was created as described previously (Yu et al., 2008). The genetic modification enables the EGFP tagging of early nestin-expressing neuroprogenitor cells as well as the conditional ablation of these cells. Six-week-old male wild-type or hemizygous TK transgenic mice were treated with ganciclovir (GCV; $200 \mathrm{mg}$ / $\mathrm{kg} / \mathrm{d}$; Cytovene-IV, Roche Pharmaceuticals) or vehicle (saline) via osmotic mini-pumps (model 2002, Alzet; infusing rate $0.5 \pm 0.1 \mu \mathrm{l} / \mathrm{h}$ for $14 \mathrm{~d}$ ) for 4 weeks before the induction of stroke. The pumps were replaced every 2 weeks for a continuous GCV effect.

\section{Distal middle cerebral artery occlusion}

Stroke was induced unilaterally in mice according to the well established distal MCAO (dMCAO) method, with modifications (Sun et al., 2011). Because a permanent distal ligation of the MCA does not give reproducible infarct in most mouse strains, we combined it with a unilateral common carotid artery (CCA) occlusion. Anesthesia was induced with $3 \%$ isoflurane in a closed chamber and maintained with $2 \%$ isoflurane in $30 \% \mathrm{O}_{2}$ and $70 \% \mathrm{~N}_{2} \mathrm{O}$ with a facemask. Core temperature was maintained at $37 \pm 0.5^{\circ} \mathrm{C}$ with a heating blanket and rectal thermistor servoloop. The animal was placed in the supine position, and a ventral cervical midline skin incision was made. The ipsilateral (left) CCA was isolated from the adjacent vagus nerve and dissected out of the carotid sheath, and a 4-0 silk suture noose was placed across the CCA from the bottom, ready for temporary ligation. The animal was then placed in the lateral position, and a $4 \mathrm{~mm}$ incision was made on the line between the left outer canthus and the front edge of the left ear. A 1.5-mm-diameter burr hole was made with a dental drill $1.2 \mathrm{~mm}$ rostral to the anterior junction of the zygoma and temporalis bone. The main trunk of the left MCA was exposed and ligated with a square knot by 11-0 suture, followed by an immediate ligation of the ipsilateral CCA. The noose on the left CCA was removed $60 \mathrm{~min}$ later to restore the blood flow. Sham-operated mice did not receive occlusion of either the MCA or CCA.

\section{Bromodeoxyuridine labeling}

Thymidine analog bromodeoxyuridine (BrdU; Sigma) was administered intraperitoneally at $50 \mathrm{mg} / \mathrm{kg} / \mathrm{d}$ during days $4-7$ after dMCAO to track proliferating cells.

\section{Immunohistochemistry and double-immunofluorescence staining} Animals were anesthetized with an overdose of $3 \%$ isoflurane followed by exsanguination and were perfused transcardially with $4 \%$ paraformaldehyde (PFA) in $0.1 \mathrm{~mol} / \mathrm{L}$ phosphate buffer (PB), $\mathrm{pH}$ 7.4. The brains were removed from the skull and fixed overnight in 4\% PFA-PB buffer, followed by cryoprotection in $20 \%$ sucrose for an additional $24 \mathrm{~h}$. Coronal sections were cut at $40 \mu \mathrm{m}$ on a microtome (Microm HM 400) and collected serially. Immunoreactivity was determined with goat-antiDCX (C-18; 1:500; Santa Cruz Biotechnology), rabbit-anti-GFP (1:5000; Millipore), chicken anti-BrdU (1:100; Abcam), rabbit anti-GFAP (1:500; Serotec), rabbit anti-NG2 (1:500; Millipore Bioscience Research Reagents), rabbit anti-oligo-2 (1:500; Millipore Bioscience Research Reagents), rabbit anti-ionized calcium binding adapter molecule 1 (Iba-1; 1:250; Wako Chemicals), and mouse anti-NeuN (1:1000; Millipore Bioscience Research Reagents); followed by anti-mouse, anti-chicken, antirabbit, or anti-goat secondary antibodies conjugated to Cy-2 or Cy-3 (1:200) according to methods described previously (Liu et al., 2007). Fluorescence signals were detected by Zeiss LSM 510 confocal image system with a sequential scanning model and images processed by Adobe Photoshop.

\section{Fluoro-Jade C staining}

Brain sections were mounted onto slides and air dried for $60 \mathrm{~min}$, followed by treatment with $1 \%$ sodium hydroxide/ $80 \%$ ethanol for $5 \mathrm{~min}$. They were then rinsed for $2 \mathrm{~min}$ in $70 \%$ ethanol, for $2 \mathrm{~min}$ in distilled water, and then incubated in $0.06 \%$ potassium permanganate solution for $10 \mathrm{~min}$. Following a 1-2 min water rinse, the slides were transferred to a $0.0001 \%$ solution of Fluoro-Jade C (dissolved in $0.1 \%$ acetic acid; Histo-Chem), and stained for $10 \mathrm{~min}$. The slides were then rinsed three times in distilled water, $1 \mathrm{~min}$ for each rinse. Following the drainage of water, the air-dried slides were then cleared in xylene for $2 \mathrm{~min}$ and coverslipped with DPX (Sigma) nonfluorescent mounting media. The staining results were visualized and imaged with a Zeiss Axioscope II epifluorescence microscope using an FITC filter.

\section{Cell counting}

DCX-immunoreactive cells in the DG were counted by unbiased stereology (StereoInvestigator, MicroBrightfield) in every sixth coronal section spanning the septal hippocampi (Wang et al., 2011b). Counting frames of $40 \times 40 \times 40 \mu \mathrm{m}$ were used in $80 \times 80 \mu \mathrm{m}$ matrices that were randomly superimposed onto the region of interest (ROI) by the program with guard zones of $3 \mu \mathrm{m}$ in each direction. EGFP-positive cells were counted manually in the septal hippocampi due to the sparse number of cells located in the ROI. EGFP cells in the SVZ were also counted manually for the same reason in three serial $40-\mu \mathrm{m}$-thick sections, spaced $240 \mu \mathrm{m}$ apart from a bregma level $0.98-0.50 \mathrm{~mm}$ under $400 \times$ magnification with a Zeiss Axio-II microscope.

\section{Quantification of synaptic connectivity}

Synaptic connectivity in the perforant pathway was determined by the degree of transsynaptic spread of the pseudorabies virus (PRV). TK ${ }^{+}$ mice were treated with either vehicle or GCV beginning at 6 weeks of age, and treatment continued for 4 weeks after dMCAO or sham surgery at 10 weeks of age. Four weeks after dMCAO or sham surgery, mice were each microinjected with $60 \mathrm{nl}$ of PRV614-RFP (titer: $1.86 \times 10^{8} \mathrm{pfu} / \mathrm{ml}$, diluted in aCSF, which was provided by Dr. Patrick Card, University of Pittsburgh, Pittsburgh, PA) into the DG (anteroposterior, $2.05 \mathrm{~mm}$; lateral, $2.25 \mathrm{~mm}$; ventral, $2 \mathrm{~mm}$ ) through a predrilled burr hole via a stereotaxic frame under isoflurane anesthesia. The virus-containing 
solution was loaded into a siliconized glass pipette with a $50-\mu \mathrm{m}$-inner diameter tip, and injected at a rate of $20 \mathrm{nl} / \mathrm{s}$ with Nanoject II (catalog \#3-000-204; Drummond). Following injection, the glass pipette was pulled out slowly after being held in the brain for 5 min to prevent leakage. The incision was closed with a 5-0 nylon suture. Mice were killed $48-50 \mathrm{~h}$ later after tracer injection and processed for PRV immunohistochemistry with a polyclonal rabbit anti-RFP antibody (1:2000; R10367, Invitrogen) using the standard avidin-biotin-HRP complex method (Raber et al., 2004). Immunoreactive cells in the entorhinal cortex (EC) between the bregma levels of -2.70 and -3.42 were counted and summed.

\section{Infarct volume determination}

Infarct volume was measured by subtracting the volume of intact tissue in the ipsilateral hemisphere from that in the contralateral hemisphere on Nissl-stained serial sections ( $240 \mu \mathrm{m}$ apart) by Image (NIH).

\section{Quantification of cerebral blood flow}

To monitor changes in flow conductance and cerebral blood volume (CBV) during baseline following ischemia reperfusion under a physiological state, we used optical microangiography (OMAG), a noninvasive imaging technique based on optical coherence tomography (OCT; An et al., 2010, Jia et al., 2010). Briefly, at baseline and $1 \mathrm{~h}$ after reperfusion, mice were anesthetized with $1.7 \%$ isoflurane $/ 30 \% \mathrm{O}_{2} / 68.3 \% \mathrm{~N}_{2} \mathrm{O}$. The skin over the skull was reflected, the cortex was illuminated through the skull at $1310 \mathrm{~nm}$, and the resulting backscattered and reference light was detected to produce spectral interferograms. Volumetric imaging data were collected by scanning the probe beam through a $1000 \times 500 \times 512$ voxel cube, representing $2.5 \times 2.5 \times 2 \mathrm{~mm}^{3}(x-y-z)$ of tissue. After scanning, the skin over the skull was closed, and the animal was allowed to recover. Global CBV images were rendered in the 3-D software AMIRA (Visual Imaging GmbH), then thresholded and analyzed for mean pixel intensity changes over time using ImageJ 1. Projection images of the 3-D data from baseline scans were overlayed with $72 \mathrm{~h}$ scans using MATLAB (The MathWorks). The vessel density was determined by segmenting the blood vessels from an OMAG image, producing a binary black-and-white image. The latter represents the area with functional blood flow. Following a global thresholding procedure, the vessel area density was determined by calculating the number of white pixels in the binary image and dividing it by the total number of pixels in the image. The vessel area density has a value between 0 and 1 . Vessels were chosen for analysis based on baseline scans by an individual blinded to 24 and $72 \mathrm{~h}$ outcomes.

\section{Neurobehavioral assessment}

To achieve sufficient sample size and statistical significance, stroke mice in four different experimental groups were randomized and tested in four cohorts, and the data were pooled. The total sample size for each group was as follows: $n=18$ for nestin- $\delta$-HSV-TK-EGFP transgenic mice treated with GCV $\left(\mathrm{TK}^{+} / \mathrm{GCV}\right) ; n=21$ for TK transgenic mice treated with vehicle $\left(\mathrm{TK}^{+} /\right.$vehicle $) ; n=21$ for wild-type mice treated with GCV ( TK $\left.^{-} / \mathrm{GCV}\right)$; and $n=8$ for wild-type mice treated with vehicle ( $\mathrm{TK}^{-}$/vehicle). Transgenic and wild-type mice were treated with GCV or vehicle from 6 to 18 weeks of age. Stroke was induced at 10 weeks, and behavioral tests commenced at 18 weeks of age according to the following order. At the end of behavioral tests, brain tissue was harvested to determine the number of remaining NPCs and lesion sizes.

Ladder test. Mice were trained to cross a 2-foot-long inclined ladder placed at a $6^{\circ}$ angle in three consecutive trials. The performance on the ladder was videotaped, and the percentages of footfalls (slipping through the bars) with the affected or unaffected limbs were scored and averaged in three trials (Liu et al., 2007).

Catwalk test. Mice were subjected to three consecutive runs of gait assessment using the CatWalk automated gait analysis system (Noldus Information Technology), as described previously (Wang et al., 2008, Neumann et al., 2009). Briefly, mice were trained to walk through a 1.3-m-long transparent glass plate with dim LED light beamed into the glass plate from the side of the glass (Noldus Information Technology). In a darkened environment, the light is reflected downward when the paws were in contact with the glass plate. The images of the footprints were captured by the camera located under the walkway. Following the identification and labeling of each footprint, the stance time, maximal contact mean intensity, and maximal area were derived from the program and averaged from the three trials.

Barnes maze test. The Barnes maze was used to evaluate spatial memory acquisition and retention. A $120-\mathrm{cm}$-diameter circular platform with forty 5 -cm-diameter holes along the perimeter (Hamilton Kinder), positioned at $60 \mathrm{~cm}$ above the floor. Mice were discouraged to idle around aimlessly by four blowing fans around the platform and 500 lux of bright light from above. A black acrylic escape tunnel $(19 \times 6 \times 5 \mathrm{~cm}$ in size $)$ was placed under one hole. During the learning days, mice were trained to locate the escape tunnel from different counterbalanced starting positions in two successive daily sessions for 6 consecutive days. The trials were recorded and analyzed with the EthoVision 3.0 video tracking system (Noldus). The probe trial, which was performed on the day after the 6 training days, provided a putative measure for the retention of spatial memory. During the probe trials, the escape tunnel was removed, and the mouse was placed $180^{\circ}$ opposite to the hole where the escape tunnel used to be. The target hole plus a $1.8 \mathrm{~cm}$ border area was defined as the target zone. The in-zone duration and frequency of crossing of the former target zone were analyzed.

\section{Statistical analyses}

Data were expressed as the mean \pm SEM and analyzed by ANOVA, repeated-measures ANOVA, or by "mixed-model regression," followed by the Bonferroni's post hoc test when appropriate, using StatView or SAS Version 9 Proc MIXED software (SAS Institute). Differences between groups were considered significant at $p<0.05$. The relationship between the outcomes (DCX and EGFP) and the duration of exposure to GCV was assessed with linear regression and Pearson correlation $(r)$ coefficient, separately by hemisphere. The regression coefficient represents the average change in the outcome per day, and we report the $p$ values of a test of the null hypothesis of no change over time. We report $r^{2}$ as a measure of the strength of the relationship of the outcome with day.

\section{Results}

\section{Baseline and stroke-induced hippocampal NPCs are ablated by GCV in nestin- $\delta$-HSV-TK-EGFP transgenic mice}

Vehicle (saline) or GCV $(200 \mathrm{mg} / \mathrm{kg} / \mathrm{d})$ was administered to nestin- $\delta$-HSV-TK-EGFP heterozygous (abbreviated as $\mathrm{TK}^{+}$) mice for 4 weeks before the induction of stroke or sham surgery and continued for 1 more week after stroke or sham procedure. Type $1[$ nestin $(+) / \operatorname{EGFP}(+)]$ and type $2 \mathrm{~b}[\mathrm{DCX}(+)]$ NPCs were significantly reduced following short-term GCV treatment (GCV effect on EGFP: $F_{(1,9)}=54.7, p<0.0001$; GCV effect on DCX: $F_{(1,9)}=30.9, p<0.0005$; Fig. 1). Stroke had a tendency to stimulate the proliferation of the remaining type I NPCs (stroke effect on EGFP: $F_{(1,9)}=4.6, p=0.06$; Fig. $1 B$ ), leading to an increase in the type 2b DCX cells (stroke effect on DCX: $F_{(1,9)}=10.2, p<$ 0.05; Fig. 1C). However, there were still fewer NPCs in the DG of GCV-treated $\mathrm{TK}^{+}$mice than in vehicle-treated $\mathrm{TK}^{+}$mice. There was no interaction between stroke and GCV treatment on either EGFP or DCX immunoreactivity. The $z$-stack analysis indicated that there was no colocalization between EGFP and DCX markers, suggesting that the expression of each marker corresponds to a distinct stage of development. A high level of dendritic arborization was commonly observed in type 1 NPCs in the DG of vehicle-treated, sham-operated mice compared with stroke mice. Furthermore, GCV treatment significantly reduced the dendritic arbor (Fig. 1G).

\section{Conditional ablation of stroke-induced NPCs by GCV is duration dependent}

Previously, we demonstrated that dMCAO induced DG neurogenesis (Matsumori et al., 2006), so we next determined the effect of GCV on stroke-induced neurogenesis when continuously 

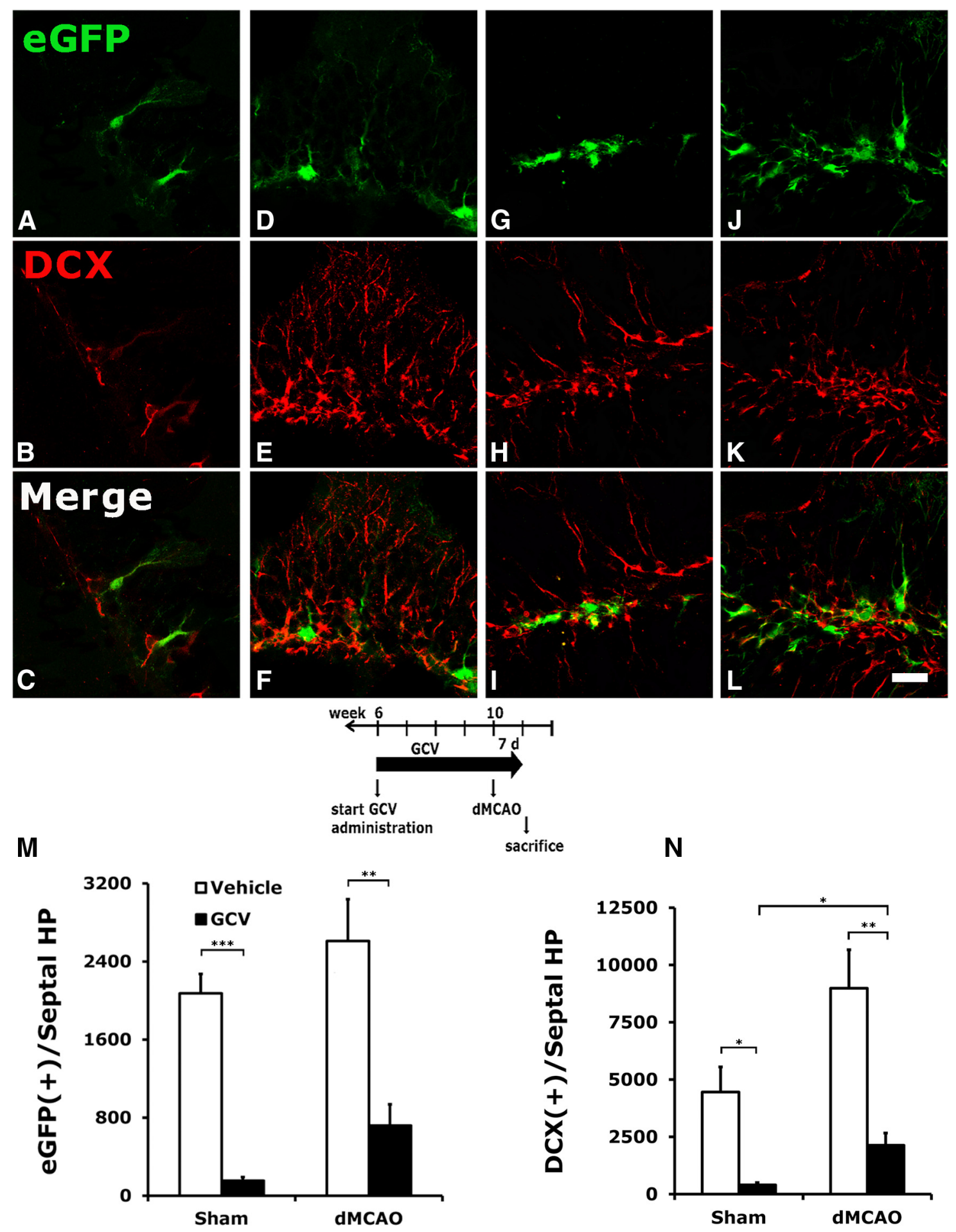

Figure 1. Conditional ablation of hippocampal NPCs by GCV in TK ${ }^{+}$mice subjected to stroke or sham surgery. $A-L$, Vehicle or GCV was administered to $\mathrm{TK}^{+}$mice for 4 weeks before stroke or sham surgery, and continued for $7 \mathrm{~d}$ after surgery until the mice were killed. Type 1 (EGFP-immunoreactive) and type $2 b$ (DCX-immunoreactive) progenitors were significantly reduced following GCV treatment in mice who had undergone either sham surgery $(\boldsymbol{A}-\boldsymbol{C})$ or a dMCAO procedure $(\mathbf{G}-\boldsymbol{I})$ compared with those treated with vehicle $(\boldsymbol{D}-\boldsymbol{F}$ and $\boldsymbol{J}-\boldsymbol{L}$, respectively). $\boldsymbol{M}, \boldsymbol{N}$, Although type $1 \mathrm{NPCS}$ in the DG showed a tendency to increase $(\boldsymbol{M})$ and type 2 cells had a significant increase $(\boldsymbol{N})$ after stroke, they were still much reduced compared with the corresponding groups in the vehicle-treated mice. GCV also reduced the degree of dendritic arborization in the type $1 \mathrm{NPCs}$ in the DG $(\boldsymbol{G})$, compared with the elaborate radial process observed in the vehicle-treated EGFP cells $(\boldsymbol{J})$. ${ }^{*} p<0.05$; ${ }^{* *} p<0.01,{ }^{* * *} p<0.005$. Scale bar, $25 \mu \mathrm{m} . N=3-4 /$ group.

present before and after dMCAO. Following the induction of stroke, $\mathrm{TK}^{+}$transgenic mice continued to receive $\mathrm{GCV}$ for $0,3,7$, 14, or $28 \mathrm{~d}$ and were killed at $28 \mathrm{~d}$ after stroke (Fig. $2 A$ ). Linear regression analysis suggests that the numbers of remaining type 1 and type 2 NPCs were inversely correlated with the duration of
GCV treatment after stroke in both hemispheres (Fig. $2 B, C$; Table 1). Early withdrawal of GCV following dMCAO did not further reduce the number of NPCs compared with those receiving GCV only before stroke. However, the groups that continued to receive GCV for 14 or $28 \mathrm{~d}$ had significantly fewer type 1 and type 
A

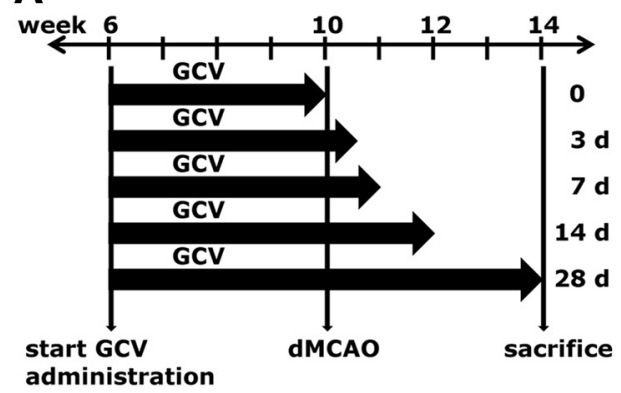

B
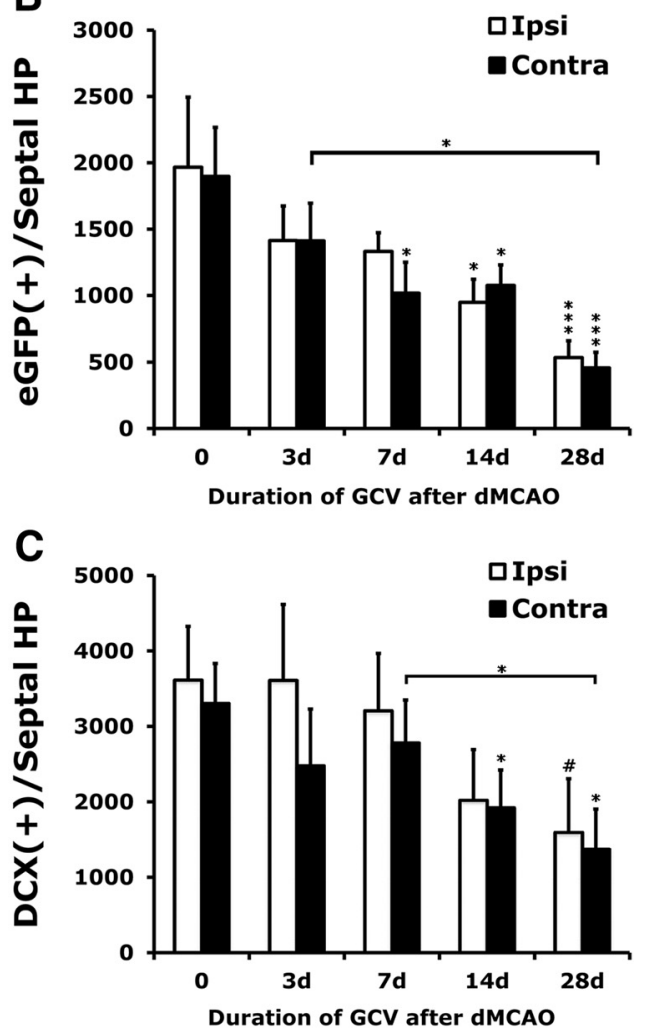

Figure 2. Following $\mathrm{dMCAO}, \mathrm{TK}^{+}$mice continued to receive GCV for $0,3,7,14$, or $28 \mathrm{~d}$ and were killed $28 \mathrm{~d}$ after stroke. $A$, Time lines of surgery, GCV treatment, and survival period. $B, C$, The numbers of EGFP-expressing $(\boldsymbol{B})$ and $D C X$-expressing $(\boldsymbol{C})$ cells in the septal hippocampus are inversely correlated with the duration of GCV treatment. Early withdrawal of GCV following dMCAO did not further significantly reduce the number of NPCs compared with mice that received GCV before stroke. However, groups that continued to receive GCV for 14 and $28 \mathrm{~d}$, and significantly fewer type 1 NPCs remained in both the ipsilateral and contralateral DG. Type 2 NPCs were affected similarly. Significant statistical results are labeled above the bar of a specific duration when compared with the $0 \mathrm{~d}$ time point of each hemisphere. Additional significant statistics are indicated between time points. ${ }^{*} p<0.05$; ${ }^{* *} p<0.01$; ${ }^{* * *} p<0.005 . N=$ 5-9/group.

Table 1. Linear regression analysis of the remaining NPCs and the days of GCV exposure

\begin{tabular}{llllll}
\hline Markers & Side & Cell count estimate per day ${ }^{a}$ & $R^{2}$ value $^{b}$ & $r$ value & Pearson $p$ value \\
\hline EGFP & Ipsilateral & -47.308 & 0.260 & -0.510 & 0.0029 \\
EGFP & Contralateral & -45.109 & 0.313 & -0.559 & 0.0009 \\
DCX & Ipsilateral & -113.825 & 0.247 & -0.497 & 0.0032 \\
DCX & Contralateral & -91.356 & 0.357 & -0.597 & 0.0002 \\
\hline
\end{tabular}

${ }^{a}$ The average decrease (per day) in cell counts for EGFP or DCX.

${ }^{b}$ The strength of the relationship of the cell counts with day.
2 NPCs remaining in the DG, suggesting that stroke-induced new type 1 and type 2 NPCs were depleted by GCV in a durationdependent fashion. There was no significant difference in the decline of either EGFP- or DCX-immunoreactive cells between the ipsilateral and contralateral hemispheres over days of treatment by mixed-model analyses (data not shown).

Stroke stimulates the proliferation of glial cells in the periinfarct cortex and type 1 NPCs in the DG

Continued GCV treatment after stroke for $7 \mathrm{~d}$ did not eliminate dividing reactive astrocytes or oligodendrocyte progenitors in the peri-infarct cortex, as evidenced by the colocalization between BrdU and GFAP, oligo-2, or NG-2, or by dividing microglia expressing BrdU/IBA-1 (Fig. $3 A-D, I$ ), suggesting that targeted ablation using the nestin promoter is indeed restricted to the NPC lineage. Some EGFP-expressing cells in the DG incorporated $\mathrm{BrdU}$, suggesting that stroke induced the proliferation of the remaining type 1 NPCs (Fig. 3E). Colocalization between BrdU and DCX also suggests that stroke-induced proliferating type 1 NPCs had successfully differentiated into DCX-expressing type 2 cells (Fig. $3 F$ ) and mature neurons (Fig. 3G). We almost never detected cells coexpressing BrdU and GFAP, which is possibly attributed to the rarity of these cells after NPC ablation (Fig. $3 \mathrm{H}, \mathrm{J}$ ).

\section{Conditional ablation of NPCs does not affect lesion size}

Consistent with previous results (Wang et al., 2011a), dMCAOinduced unilateral ischemic injury was restricted to cortex. In contrast to many degenerating neurons labeled by Fluoro-Jade $C$ staining in the cortex (Fig. $4 A, B, E, F$ ), there was no labeling in the hippocampus (Fig. 4C,D, G,H) of mice treated with either vehicle or GCV at $4 \mathrm{~d}$ after $\mathrm{dMCAO}$. There was no significant difference in the infarct size between $\mathrm{TK}^{+}$mice treated with GCV and those treated with vehicle (GCV treatment: $8.5 \pm 1.9 \mathrm{~mm}^{3}$, $n=7$; vehicle treatment: $11.7 \pm 1.2 \mathrm{~mm}^{3}, n=8$; NS), suggesting that temporary ablation of neurogenesis does not affect stroke size. Because NPCs are intimately associated with the cerebral vasculature and regulate the neurovascular unit by responding to ischemia, we determined whether ablation of the NPCs had an effect on the regulation of blood flow after stroke by OMAG, a noninvasive and high-resolution imaging modality assessing blood flow at physiological state. OMAG was used to generate projection images of actively perfused cortical vasculature and to quantify changes in $\mathrm{CBV}$ as a change in image pixel intensity relative to baseline scans. At baseline, there was no difference in mean intensities between wild-type $(0.41 \pm 0.004)$ and TK transgenic mice $(0.43 \pm 0.033 ; p>0.35)$, indicating a lack of transgene effect on the development of a functional vascular network (Fig. 5A). At $1 \mathrm{~h}$ after reperfusion, there was also no significant difference in the extent of CBV reduction in the ipsilesional hemisphere between $\mathrm{TK}^{+}$mice treated with vehicle $(8.5 \pm 1.4 \%$ of baseline) and those treated with GCV (10.1 $\pm 1.3 \%$ of baseline; $p>0.48$; Fig. $5 B)$, suggesting that the ablation of NPCs did not have an adverse effect on cerebral blood perfusion after stroke.

\section{Conditional ablation of NPCs exacerbates stroke-induced cognitive impairment}

To determine whether conditional ablation of NPCs affects stroke-induced functional impairment in learning and memory, transgenic $\mathrm{TK}^{+}$and $\mathrm{TK}^{-}$mice were treated with $\mathrm{GCV}$ or vehicle from 6 to 18 weeks of age. Stroke was induced at 10 weeks, and behavioral tests commenced at 18 weeks of age (Fig. 6A, time 

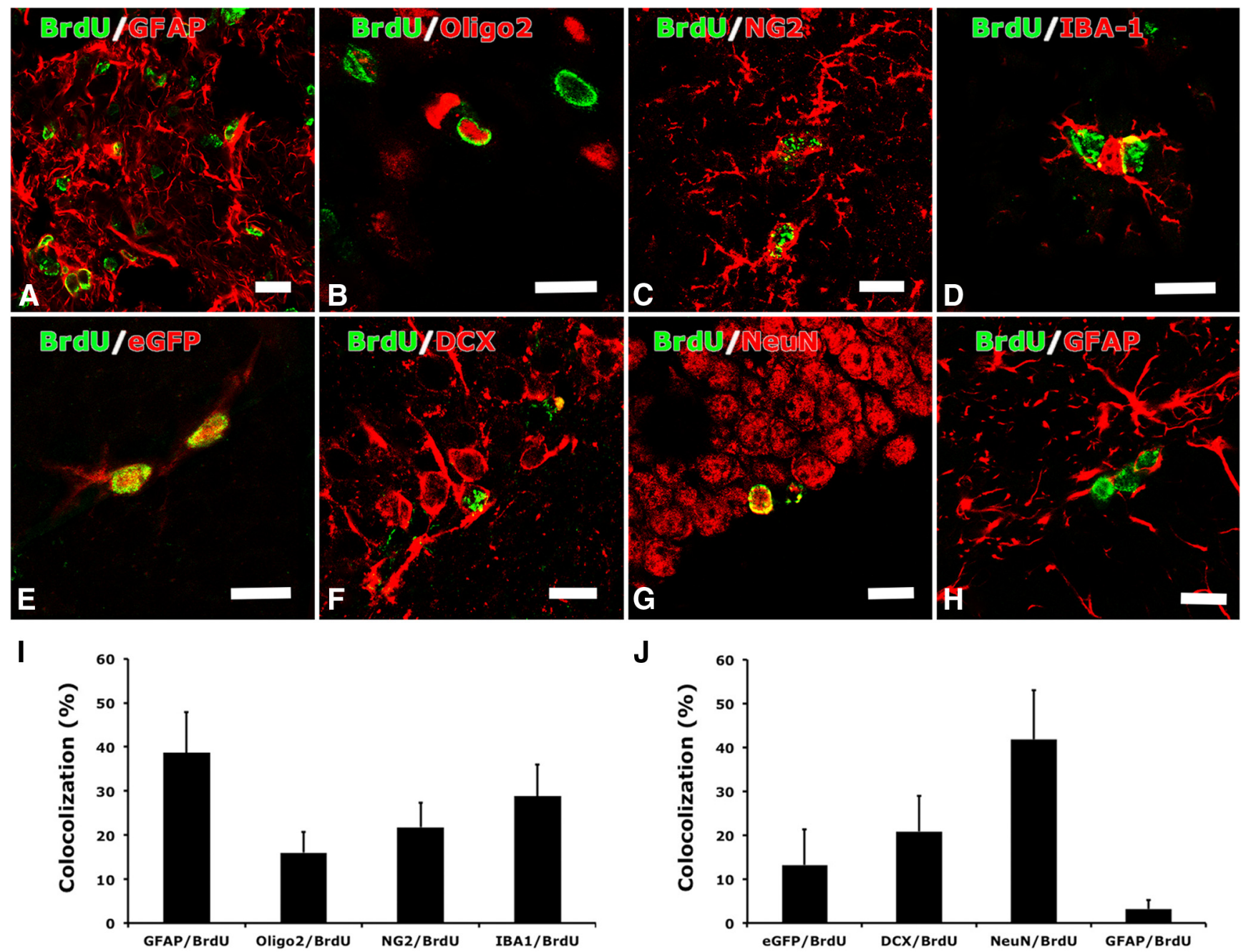

Figure 3. Stroke induced the proliferation of NPCs in the DG and glial cells in the peri-infarct cortex in the presence of GCV. Following dMCA0, TK ${ }^{+}$mice continued to receive GCV for $7 \mathrm{~d}$ and were killed after $28 \mathrm{~d}$. $\boldsymbol{A}-\boldsymbol{D}$, BrdU was given during days $4-7$ after stroke. GCV did not affect dividing reactive astrocytes $(\boldsymbol{A})$, oligo-2-expressing cells $(\boldsymbol{B})$, or oligodendrocyte progenitors $(\boldsymbol{C})$ in the peri-infarct cortex, or lba-1-expressing microglia in the infarct core $(\boldsymbol{D}) . \boldsymbol{E}, \boldsymbol{F}$, Few stroke-induced newly born NPCs in the DG survived and expressed either type 1 $(\boldsymbol{E})$ or type $2(\boldsymbol{F})$ cell markers despite the continued presence of GCV. G, A few newly divided NPCs differentiated into NeuN-expressing mature neurons and migrated into the granule cell layer. $\boldsymbol{H}$, However, colocalization between BrdU and GFAP was rarely detected in the DG. $\boldsymbol{I}, \boldsymbol{J}$, Percentages of cell type-specific markers colocalized with BrdU in the periinfarct cortex or infarct core (I) and DG (J). Scale bars, $25 \mu \mathrm{m} . N=7 /$ group.

line). Over the $6 \mathrm{~d}$ of training in the Barnes maze test, all groups of mice learned the task as demonstrated by traveling progressively less distance to locate the escape box $\left(F_{(5,320)}=71.3, p<0.0001\right)$. However, mice that received GCV traveled significantly longer distances to reach the escape box compared with vehicle-treated mice (two-way repeated-measures ANOVA, GCV effect: $F_{(1,64)}=$ $4.4, p<0.05$; Fig. $6 B$ ). There was a borderline effect of the transgene on search path length $\left(F_{(1,64)}=3.4, p=0.06\right)$. There was also a significant interaction between GCV treatment and genotype over days of learning (day $\times$ GCV $\times$ genotype interaction: $\left.F_{(5,320)}=2.3, p<0.05\right)$. Post hoc analyses suggest that ischemic $\mathrm{TK}^{+}$mice treated with 16 weeks of GCV performed significantly worse in the Barnes maze test compared with their counterparts treated with vehicle $(p<0.005)$ or with ischemic wild-type mice treated with GCV $(p<0.01$; Fig. $6 B)$. There was no significant difference in the path length taken to escape the box between ischemic wild-type mice, which do not carry the viral TK transgene, treated with GCV, and those treated with vehicle $(p>$ $0.78)$. This suggests that the observed functional impairment in the transgenic stroke mice treated with GCV was a consequence of attenuating neurogenesis and was not related to the potential toxicity of GCV.

Furthermore, $\mathrm{TK}^{+}$stroke mice treated with GCV had deficits in retaining spatial memory when compared with any other group. These mice spent less time searching the former target zone during the probe trial (Fig. 6C) and crossed the former target zone less frequently than $\mathrm{TK}^{+}$stroke mice treated with vehicle (Fig. 6D). Immunohistochemistry data confirmed that chronic treatment with GCV effectively depleted the number of type 1 and type 2 NPCs in $\mathrm{TK}^{+}$mice with stroke with little sign of recovery, despite the removal of GCV during the 2 weeks of behavioral tests (Fig. 6E,F).

\section{Conditional ablation of NPCs reduces SVZ neurogenesis but} does not worsen poststroke motor function

Using the catwalk automated gait analysis method, we found that the conditional ablation of NPCs did not significantly affect gait parameters, including stance, paw pressure, and the area of paw contact, among mice that underwent dMCAO (Fig. $7 A-C$ ). Nor did it affect the extent of foot fault when traversing an elevated 

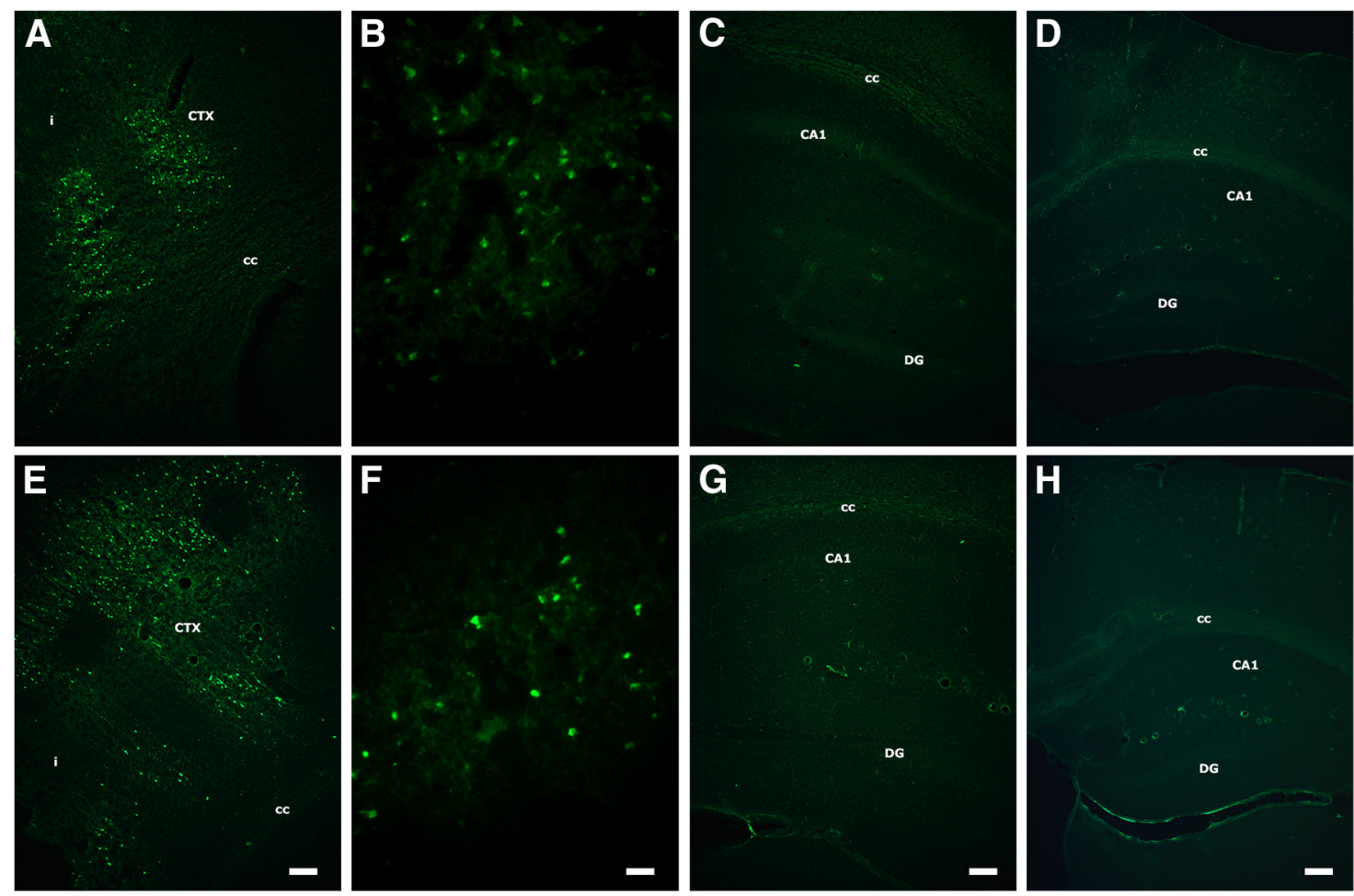

Figure 4. Distal occlusion of MCA does not induce injury in the hippocampus. $\boldsymbol{A}-\boldsymbol{H}$, Fluoro-Jade $\mathrm{C}$ was used to label degenerating neurons in mice treated with vehicle $(\boldsymbol{A}-\boldsymbol{D})$ or $\mathrm{GCV}(\boldsymbol{E}-\boldsymbol{H})$ at $4 \mathrm{~d}$ after dMCA0. There was no Fluoro-Jade C staining in the ipsilateral $(\boldsymbol{C}, \boldsymbol{G})$ or contralateral $(\boldsymbol{D}, \boldsymbol{H})$ hippocampus, indicating no sign of injury. However, robust Fluoro-Jade $($ labeling was seen in the peri-infarct region ipsilateral to ischemic stroke in both groups $(\boldsymbol{A}, \boldsymbol{B}, \boldsymbol{E}, \boldsymbol{F}) . \boldsymbol{B}$ and $\boldsymbol{F}$ are $40 \times$ magnification of $\boldsymbol{A}$ and $\boldsymbol{E}$. i, Ischemic infarct; $(\mathrm{CTX}$, cortex; cc, corpus callosum; DG, dentate gyrus. Scale bars: $A, E, 100 \mu \mathrm{m} ; \boldsymbol{B}, \boldsymbol{E}, 25 \mu \mathrm{m} ; \boldsymbol{C}, \boldsymbol{G}, 100 \mu \mathrm{m} ; \boldsymbol{D}, \boldsymbol{H}, 200 \mu \mathrm{m} . N=4-5 / \mathrm{group}$.

horizontal ladder (Fig. 7D). Despite a general lack of worsening in motor function, GCV effectively reduced the number of type 1 and type 2 NPCs in the SVZ (Fig. 7E-G). However, GCV-induced conditional ablation of type 1 NPCs was less pronounced in the SVZ than in the DG in mice that underwent dMCAO (ablation rate of type 1 NPCs in SVZ vs DG: $32.1 \%$ vs 58.3\%, respectively).

\section{Conditional ablation of NPCs reduces synaptic connectivity} in the perforant pathway after stroke

The glutamatergic input from EC projects to the DG; therefore, new neurons can modulate the activity of interneurons and neighboring granule neurons. To determine whether the conditional ablation of NPCs affects synaptic connectivity in the perforant pathway after stroke, mice were injected with the retrograde transsynaptic neuronal tracer PRV-614-RFP in the DG at 4 weeks after stroke. Both $\mathrm{dMCAO}$ and the conditional ablation of NPCs reduced the spread of PRV614 into the EC (stroke effect, $p<0.001$; GCV effect, $p<0.005$ ). Among mice with stroke, GCV treatment further reduced the retrograde spread of PRV-614RFP in the EC (Fig. 8A-C). In addition, regression analysis indicated that there was a positive correlation between the viral infectivity in the EC and the number of DCX-positive cells in the DG $(p<0.05$; Fig. $8 D)$.

\section{Discussion}

While a functional role for adult hippocampal neurogenesis in spatial learning and memory has been well established (for review, see Deng et al., 2010, Aimone et al., 2011), the contribution of neurogenesis in the recovery of cognitive function after ischemic brain injury remains unclear. Using a transgenic mouse model containing a modified HSV TK gene driven by the nestin promoter, we demonstrated that the ablation of NPCs impeded
A

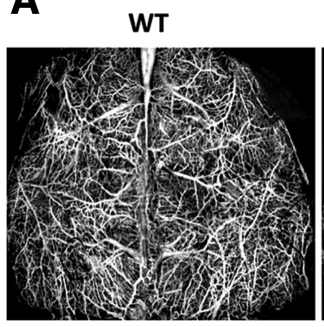

B

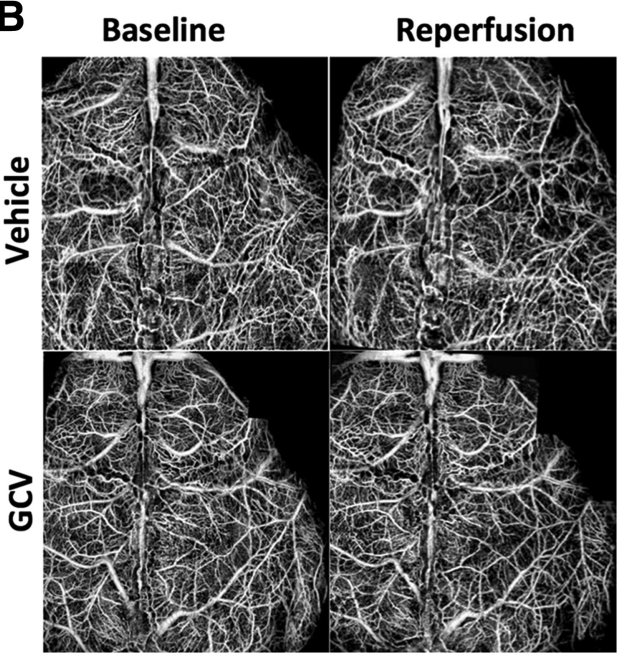

Figure 5. Conditional ablation of NPCs does not affect functional blood flow during reperfusion. $A$, Representative $0 C T$ images revealed no significant difference in baseline functional vascular network between wild-type and TK transgenic mice, suggesting a lack of transgene effect on the development of cerebrovasculature. $\boldsymbol{B}$, There was also no significant difference in cerebral blood flow in the ipsilesional hemisphere during $1 \mathrm{~h}$ after reperfusion between TK transgenic mice treated with vehicle and those with GCV.N $=3-6 /$ group. 
A

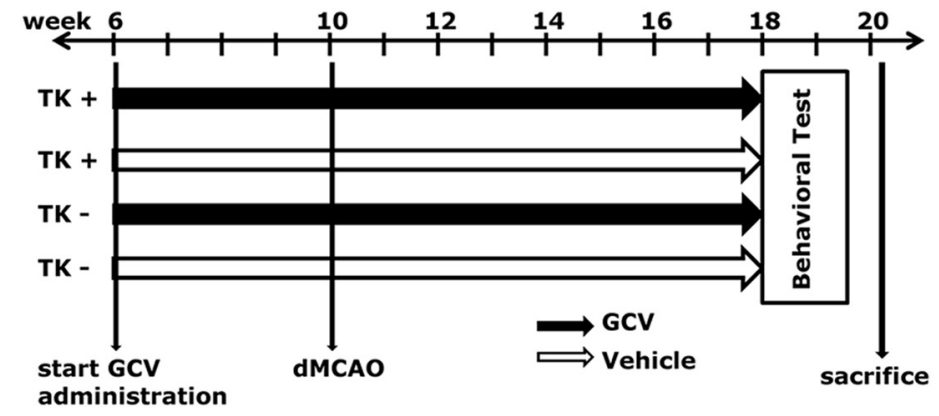

B
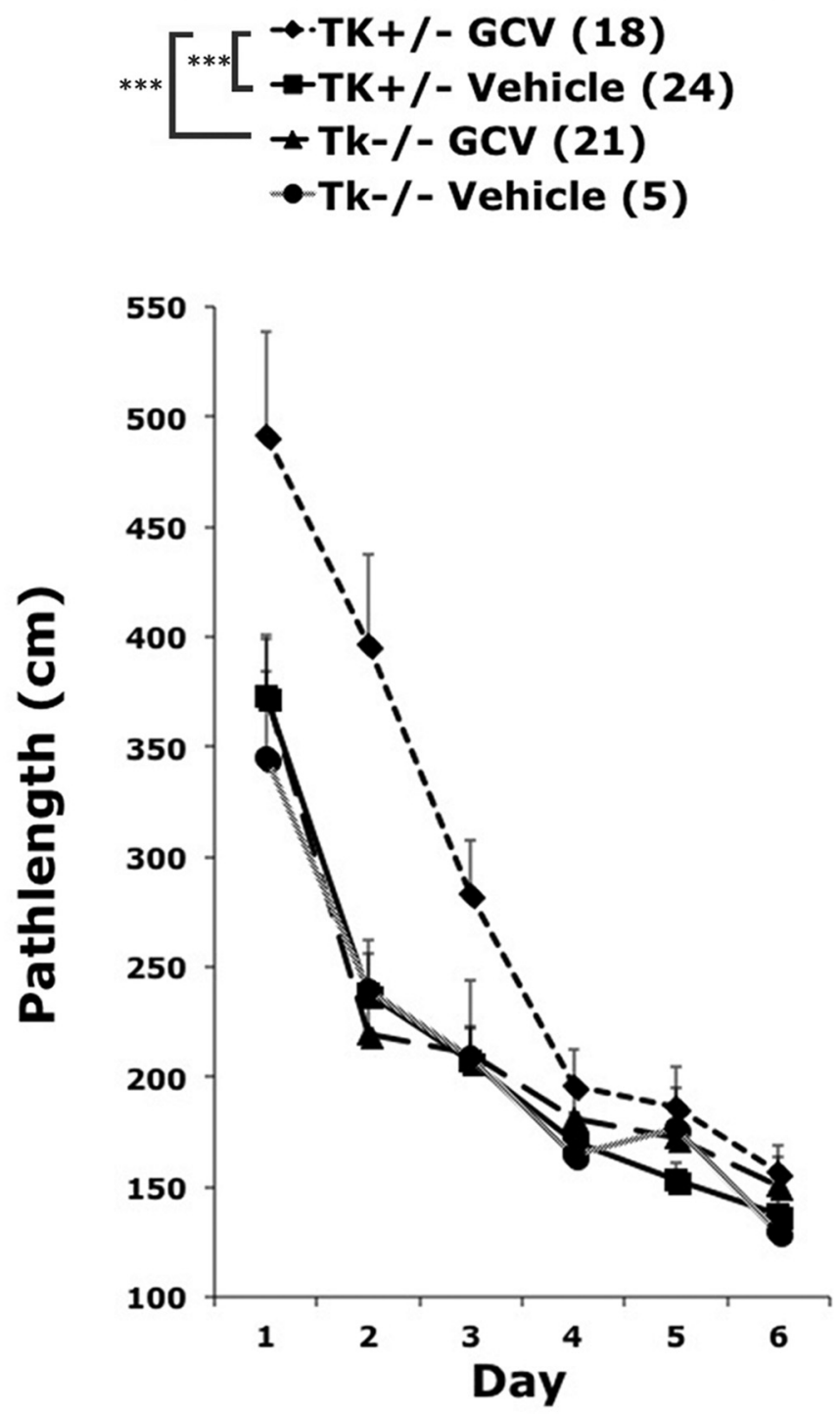

C

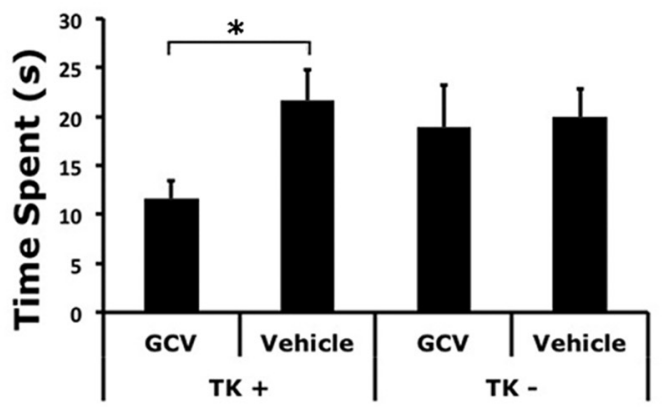

D

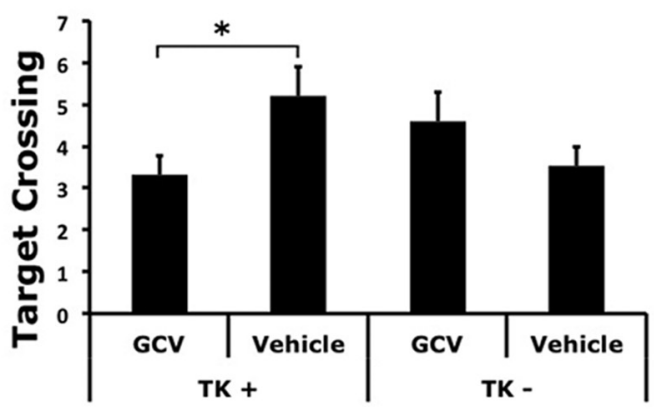

$\mathbf{E}$

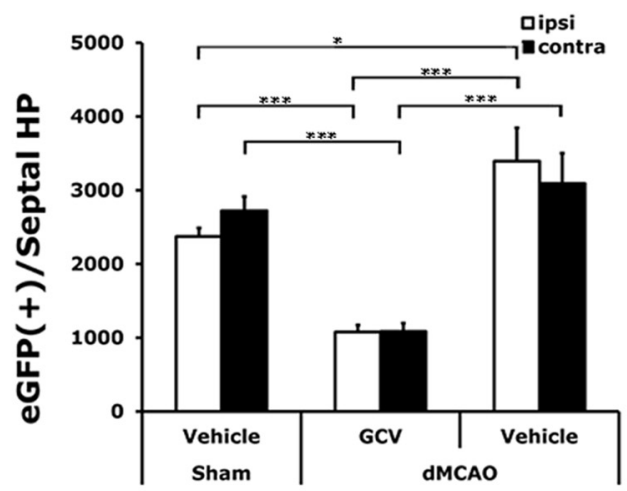

F

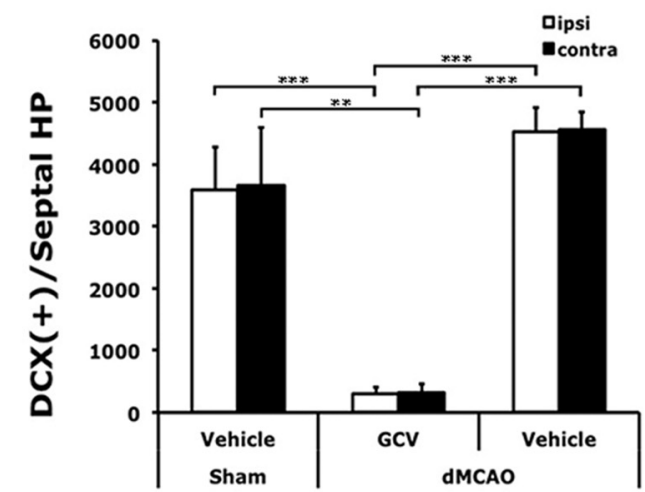

Figure 6. Conditional ablation of NPCs impaired poststroke spatial learning and memory function in the Barnes maze test. $\boldsymbol{A}$, Time lines of surgery and drug treatment. $\boldsymbol{B}$, Chronic treatment of $\mathrm{GCV}$ in $\mathrm{TK}^{+}$mice subjected to stroke worsened the acquisition rate over $6 \mathrm{~d}$ in the Barnes maze test compared with vehicle treatment $\left({ }^{* * *} p<0.005\right)$ or compared with ischemic $\mathrm{TK}^{-}$mice that do not carry the $\delta$-HSV-TK transgene while being treated with $\mathrm{GCV}\left({ }^{* *} p<0.01\right.$ ). Neither GCV treatment of wild-type mice with stroke (TK ${ }^{-} \mathrm{GCV}$ v $\mathrm{TK}^{-}$vehicle: $p>0.78$ ) nor transgene in the absence of $\mathrm{GCV}\left(\mathrm{TK}^{+}\right.$Vehicle vs TK ${ }^{-}$vehicle: $p>0.92$ ) significantly affected the performance of stroke mice in the Barnes maze test. $\boldsymbol{C}, \boldsymbol{D}$, Stroke mice with reduced neurogenesis also exhibited impairment in memory recall/retention, as evidenced by reduced time spent in searching the target zone $(\boldsymbol{C})$ and reduced frequency of crossing (D). $E, F$, Corroborating evidence indicated that chronic treatment of $\mathrm{GCV}$ significantly depleted the number of type 1 and type $2 \mathrm{NPCs}$ in mice subjected to dMCA0, respectively. ${ }^{*} p<0.05$; ${ }^{* *} p<0.01 ;{ }^{* *} p<0.005$. Group sizes are as indicated. 
A

口TK+ / GCV

口TK + / Vehicle

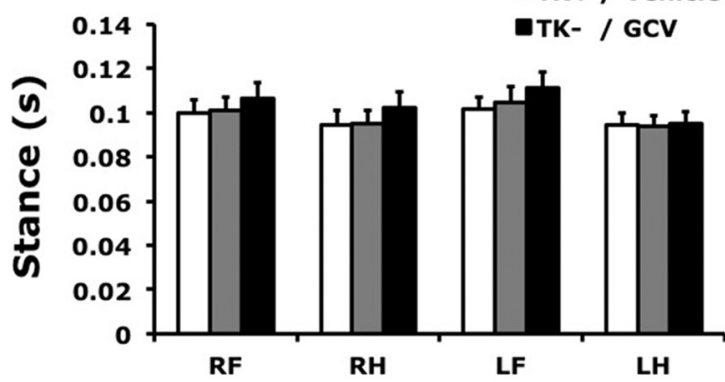

B

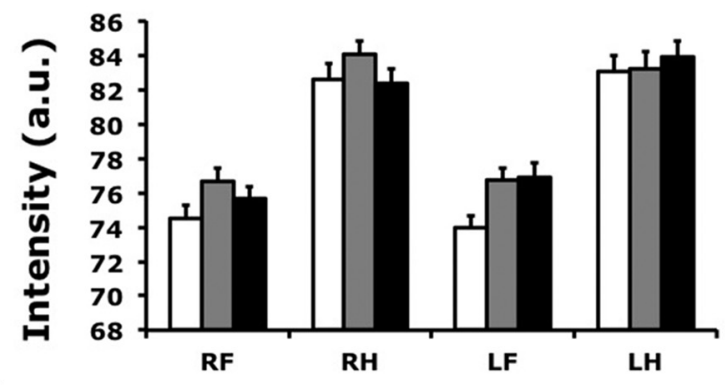

C
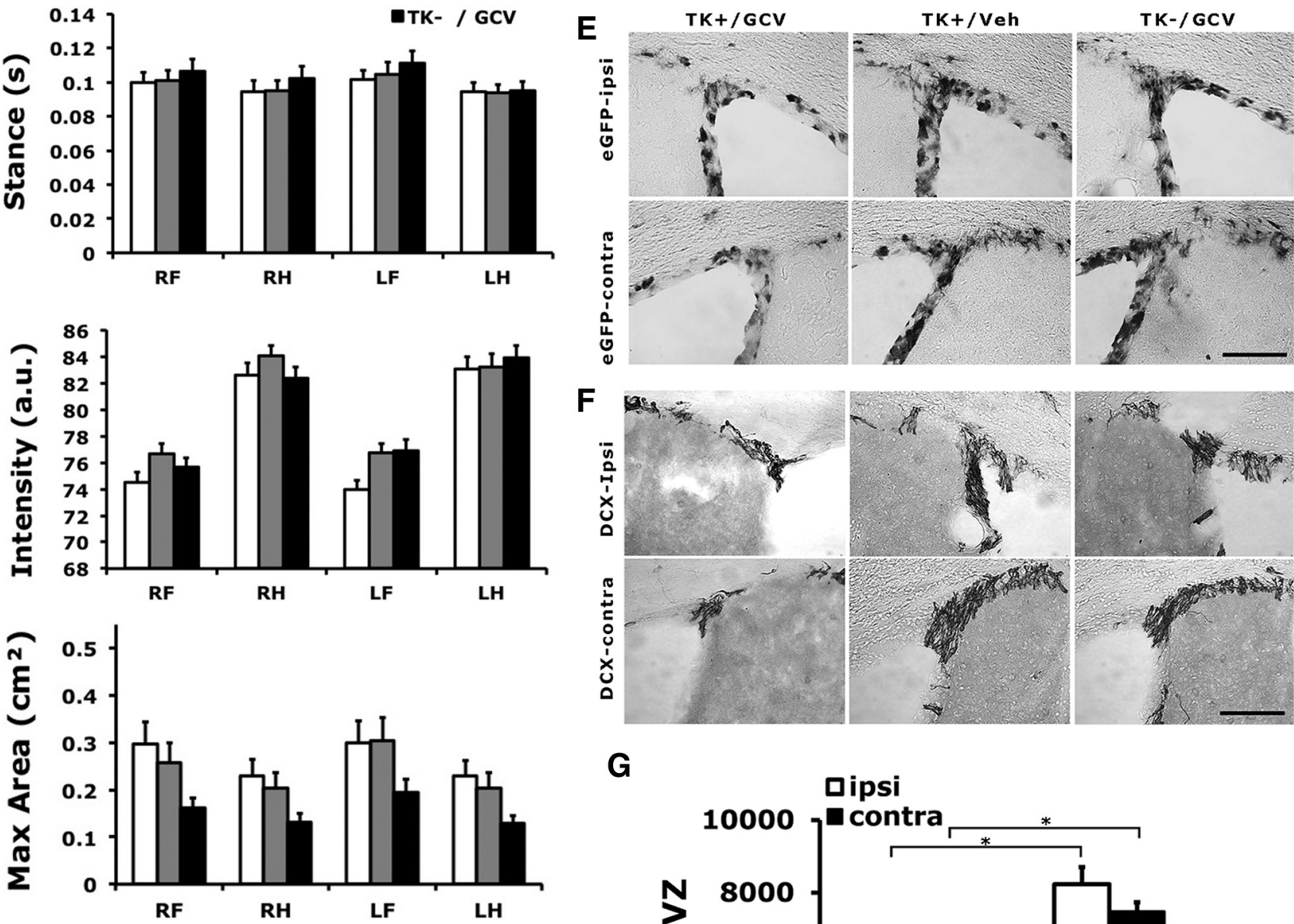

G
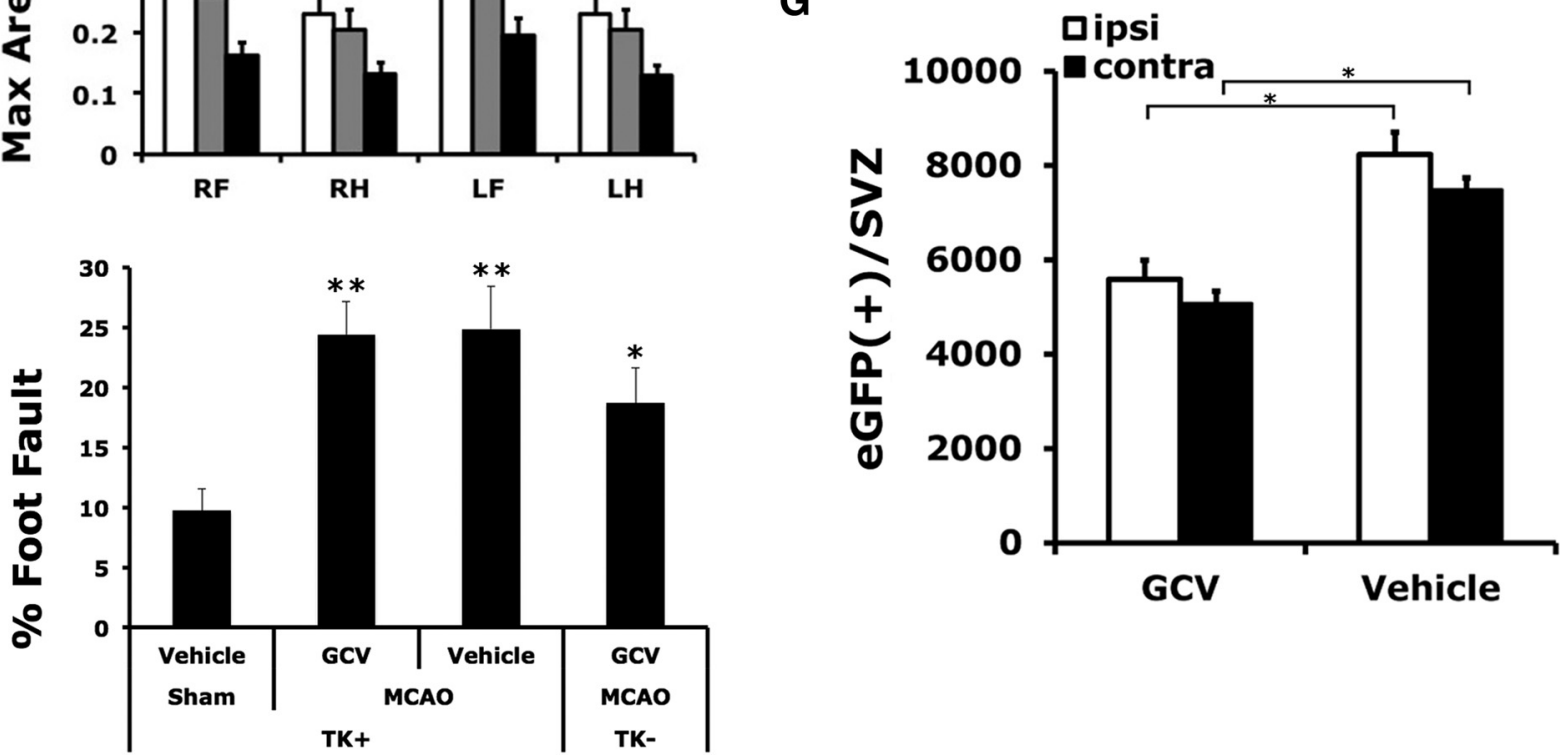

GCV

Vehicle

Figure 7. Conditional ablation of NPCs did not significantly affect the recovery of poststroke motor function. $\boldsymbol{A}-\boldsymbol{D}$, There was no significant difference in gait function perimeters (intensity, maximum contact area, and stance; $\boldsymbol{A}-\boldsymbol{C})$ or the extent of foot fault when traversing an elevated horizontal ladder $(\boldsymbol{D})$ among $\mathrm{TK}^{+}$stroke mice treated with $\mathrm{GCV}$, $\mathrm{TK}^{+}$stroke mice treated with vehicle, and $\mathrm{TK}^{-}$mice stroke treated with GCV, compared with $\mathrm{TK}^{+}$vehicle-treated, sham-operated mice. Regardless of genotype or treatment, stroke mice stepped through the ladder more often than the sham-operated mice. $\boldsymbol{E}, \boldsymbol{F}$, Representative photomicrographs showing the expression of EGFP $(\boldsymbol{E})$ and $D C X(\boldsymbol{F})$ in groups as indicated. $\boldsymbol{G}$, There was a significant reduction in the type $1 \mathrm{NPC}$ in the SVZ in the $\mathrm{TK}^{+}$mice treated with GCV compared with those treated with vehicle. Scale bars, $100 \mu \mathrm{m}$. Comparison with the sham group: ${ }^{*} p<0.05 ;{ }^{* *} p<0.01 . N=18-24 /$ group.

the recovery of cognitive but not motor function after stroke. The worsened learning and memory outcome observed in mice with reduced neurogenesis compared with those with an intact NPC pool was not related to the potential adverse effect of NPC ablation on stroke lesion size, which did not differ between the two groups. We also found that the ablation of NPCs was associated with a decreased retrograde spread of the polysynaptic marker PRV in the perforant pathway, suggesting a possible role of reduced synaptic connectivity in impaired cognition.
The role of neurogenesis in mediating recovery and repair after brain ischemia has just begun to emerge. In a recent report in which type 2 NPCs were targeted via a viral TK gene under the control of the DCX promoter, a 2 week GCV pretreatment not only markedly reduced baseline and stroke-induced DCXexpressing cells, but also reduced motor function and resulted in larger infarct at $24 \mathrm{~h}$ after stroke (Jin et al., 2010). These data suggest that the ablation of DCX-expressing cells before stroke might have an adverse effect on overall neuroprotection, which 
A

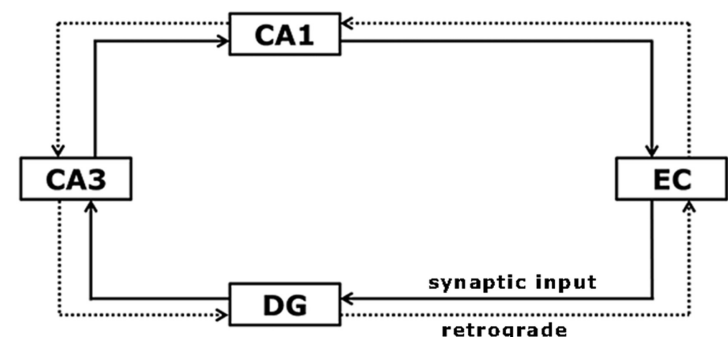

B

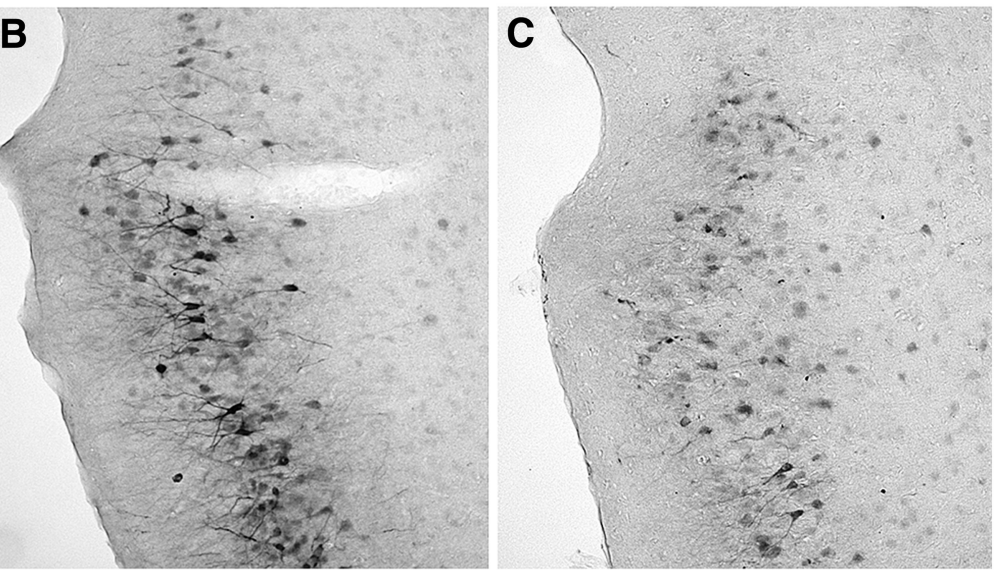

D

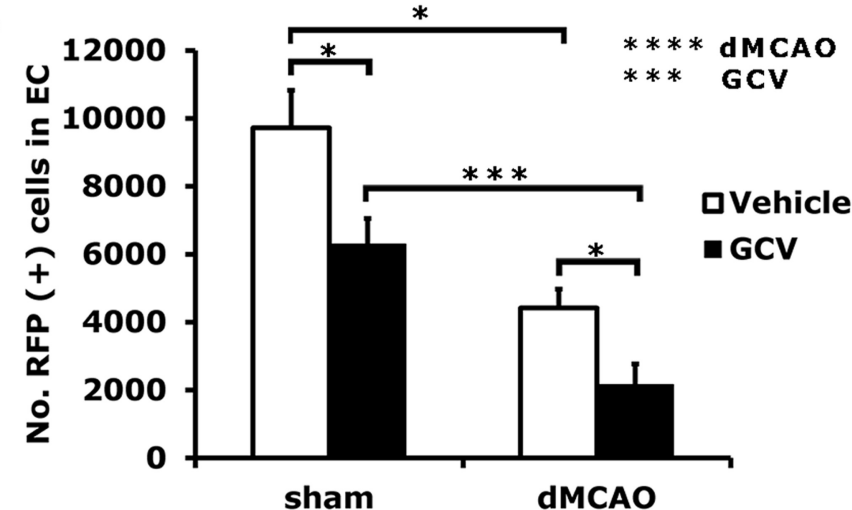

$\mathbf{E}$

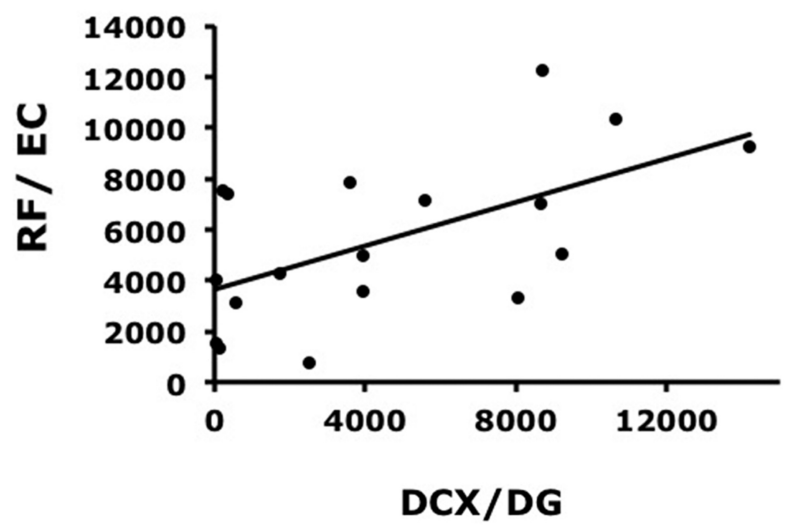

Figure 8. Conditional ablation of NPCs reduced synaptic connectivity in the perforant pathway. $A$, Trisynaptic circuits of the hippocampal network are shown in the diagram. Retrograde synaptic tracer PRV614 was injected into the DG at 4 weeks after stroke or sham surgery. $\boldsymbol{B}, \boldsymbol{C}$, Representative images of cells immunopositive for RFP from $\mathrm{TK}^{+}$mice treated with vehicle $(\boldsymbol{B})$ and with $\mathrm{GCV}(\boldsymbol{C})$, and subjected to stroke. $\boldsymbol{D}$, Retrograde spread of the virus from the DG to EC was quantified as shown. Conditional ablation of NPCs by GCV as well as stroke both reduced the spread of PRV614 into EC. $E$, Regression analysis suggested that there was a positive correlation between the number of DCX-positive cells in the DG and PRV614 infectivity in the $\mathrm{EC}(p<0.05) . Y=3639.6+0.4 \mathrm{X} ; R^{2}=0.34 . N=4-6 /$ group. was reflected as worse lesion size and motor function. The neuroprotective role of DCX has been supported by an in vitro study showing that overexpression of DCX protected cultured SVZ cells from cell death induced by oxygen and glucose deprivation (Santra et al., 2006). In a follow-up study, the authors showed that ablating DCX-expressing cells for 2 weeks before stroke only transiently affected some motor test performance 3 months later, despite a nearly $50 \%$ greater lesion volume due to DCX depletion. They also found that neurogenesis was normalized at 12 weeks after MCAO, but the dynamics of NPCs during the first few weeks after ischemic stroke was not assessed (Wang et al., 2012). Although it remained possible that the equalized motor deficits were related to the restoration of neurogenesis after GCV was discontinued, the alternative explanation could be that at 12 weeks after dMCAO the natural recovery of motor function in all experimental groups rendered the difference below the threshold of detection.

Contrary to the results of Jin et al. (2010), we found that the ablation of nestin-expressing NPCs beginning at 1 month before stroke did not increase infarct size, suggesting that the temporary depletion of type 1 NPCs does not exacerbate ischemic injury. This is consistent with an earlier study examining the relationship between neurogenesis and functional outcome after global ischemia using low doses of cranial irradiation ( $\mathrm{Ra}$ ber et al., 2004), in which irradiation effectively reduced DG neurogenesis, but it did not worsen ischemia-induced cell loss in the CA1. Despite the trophic support from NPCs in stabilizing the neurovascular unit, we did not observe significant difference in postischemic reperfusion, suggesting that conditional ablation of NPCs alone did not alter the vascular response to stroke, which is likely attributable to the lack of effect on lesion size. Second, unlike the temporary ablation paradigm used in their study, we found that a continuous treatment with GCV effectively ablated new neurons born after stroke, providing a genuine assessment of the functional role of poststroke neurogenesis. This conditional ablation in the current study was targeted at NPCs, as it did not prevent the proliferation of astrocytes, oligodendrocytes, or microglia in the ischemic cortex. The effect of GCV on learning and memory appears to be specifically related to the depletion of NPCs rather than a global toxic effect, since wild-type mice that underwent dMCAO and were treated with 
GCV performed similarly to vehicle-treated TK mice with stroke in the Barnes maze test.

Despite effective ablation of NPCs in the SVZ after stroke in our study, we were unable to detect significant reduction in motor function in stroke mice treated with GCV compared with those treated with saline or wild-type stroke mice treated with GCV. The reason for this lack of effect following conditional ablation is not clear. It was unlikely to be due to the natural recovery of motor function or a general lack of sensitivity in the motor function tests used, because the ladder test detected $\sim 20$ $25 \%$ of foot faults of the affected limb among all groups, at the level of deficit comparable to our previous results (Liu et al., 2007). Regarding SVZ neurogenesis, several reports indicate that a small portion of SVZ-derived cells migrated into striatum and assumed features of mature neurons with action potentials after stroke (Hou et al., 2008), although most SVZ newborn cells died during migration (Arvidsson et al., 2002). It remains unclear whether the surviving new neurons contribute to the natural recovery of motor function after stroke despite their electrophysiological properties.

Recently developed genetic tools to ablate NPCs add to our understanding of the functional role of neurogenesis. For example, targeting SGZ-derived neurons that have already become committed to the memory trace via the combination of diphtheria toxin (DT) receptor tagging in NPCs and DT administration induces retrograde memory deficits (Arruda-Carvalho et al., 2011). Inhibiting Wnt signaling locally in the DG by injecting dnWnt-expressing lentivirus into the DG not only reduces neurogenesis, but also affects spatial pattern separation (Clelland et al., 2009). Per computational models, the fine-tuning property of DG neurons in pattern separation is essential in information processing to avoid interference between memories (Leutgeb et al., 2007, Deng et al., 2010, Aimone et al., 2011). Conversely, increasing hippocampal neurogenesis by conditional ablation of the apoptosis-inducing gene Bax in neural stem cells can improve pattern separation in the $i B a x^{n e s t i n}$ mice (Sahay et al., 2011). Complementary to these findings, independent reports have demonstrated that ablating neurogenesis results in impaired spatial memory by either inducible expression of the proapoptotic protein Bax in the NPCs of nestin-rtTA/TRE-BAX mice (Dupret et al., 2008) or by inducible expression of diphtheria toxin fragment A in the NPCs of nestin-CreER/NSE-DTA mice (Imayoshi et al., 2008). Together, despite variations in the ablation approach and experimental design, a confluence of evidence has consistently suggested an involvement of adult-born DG neurons in learning and memory.

According to the pattern separation theory, DG neurons are involved in controlling "memory resolution" (i.e., the extent of information encoding by the DG and downstream hippocampal pathways: DG $\rightarrow$ CA3 $\rightarrow$ CA1 $\rightarrow$ EC). Considering the cell turnover in this region, depriving the DG of new granule neurons would not only diminish the encoding capacity, but possibly jeopardize neuronal connections in the network, particularly in a damaged brain after stroke, as suggested by our data. Because neuronal networks are highly plastic and reorganize with activity, changes at the neuronal network level are very likely to underlie ischemia-induced functional deficits and associated recovery. Indeed, $\gamma$ oscillation, normally suppressed by EC inputs (Bragin et al., 1995), was increased following $\mathrm{dMCAO}$ with altered frequency and amplitude (unpublished observation). It suggests that dMCAO modifies hippocampal activity, possibly via reduced synaptic input from the EC due to either local changes at $\mathrm{EC}$ or indirect changes from ischemic parietal cortex to the hip- pocampus. In turn, newly born neurons could play a role in restoring poststroke hippocampal circuit dynamics, which normally receives excitatory drives from the cortex. In support of this notion, the excitation-neurogenesis coupling hypothesis suggests that adult hippocampal neural stem cells/progenitor cells possess an activity-sensing capability by acting, in part, via NMDA receptors and $\mathrm{Ca}^{2+}$ channels, to adapt the adult neural network in response to both physiological demands and pathological insults (Deisseroth et al., 2004). Previously, we found that housing in an enriched environment not only increased hippocampal neurogenesis, reversed ischemia-induced memory impairment, but also reinstated neuronal activation within the hippocampal circuit, indicating that rescuing hippocampal activity was sufficient to alleviate the observed spatial memory deficits despite permanent cortical damage (Wang et al., 2011a).

Parallel to the evidence in hippocampal activity, we also examined the synaptic connectivity in the hippocampal network after ischemic stroke that may underlie the behavioral deficits. In the current study, we performed retrograde tracing with PRV, of which the transneuronal spread depends on synaptic connections (Lee and Erskine, 2000, Rinaman et al., 2000, Kim et al., 2002). We found that stroke chronically reduced the synaptic spread of PRV in the perforant pathway, and conditional ablation of NPCs further impaired the connectivity in this pathway, providing a mechanistic insight into the exacerbated learning and memory observed in the current study. In addition to the diminished connectivity in the perforant pathway, the ablation of NPCs can also potentially reduce synaptic contact between new granule neurons and hilar interneurons, mossy cells, or CA3 pyramidal neurons, ultimately affecting the entire hippocampal circuitry (Toni and Sultan, 2011, Song et al., 2012). Although the preservation of existing hippocampal circuits might be a secondary effect of neurogenesis, our results suggest that continuous neurogenesis after ischemic stroke is required to maintain a functional network involved in hippocampal-dependent memory. However, the limitation of rodent models of stroke lies in the lack of appropriate means to determine cognitive impairment common to human stroke patients in domains other than spatial memory, including executive functioning and processing speed. Whereas our data do not completely resolve the issue of the functional role of neurogenesis in humans after stroke, they do strongly indicate that an intact regeneration process is crucial in maintaining cognitive function in a damaged brain.

\section{References}

Aimone JB, Deng W, Gage FH (2011) Resolving new memories: a critical look at the dentate gyrus, adult neurogenesis, and pattern separation. Neuron 70:589-596. CrossRef Medline

An L, Qin J, Wang RK (2010) Ultrahigh sensitive optical microangiography for in vivo imaging of microcirculations within human skin tissue beds. Opt Express 18:8220-8228. CrossRef Medline

Arruda-Carvalho M, Sakaguchi M, Akers KG, Josselyn SA, Frankland PW (2011) Posttraining ablation of adult-generated neurons degrades previously acquired memories. J Neurosci 31:15113-15127. CrossRef Medline

Arvidsson A, Collin T, Kirik D, Kokaia Z, Lindvall O (2002) Neuronal replacement from endogenous precursors in the adult brain after stroke. Nat Med 8:963-970. CrossRef Medline

Bragin A, Jandó G, Nádasdy Z, Hetke J, Wise K, Buzsáki G (1995) Gamma $(40-100 \mathrm{~Hz})$ oscillation in the hippocampus of the behaving rat. J Neurosci 15:47-60. Medline

Clelland CD, Choi M, Romberg C, Clemenson GD Jr, Fragniere A, Tyers P, Jessberger S, Saksida LM, Barker RA, Gage FH, Bussey TJ (2009) A functional role for adult hippocampal neurogenesis in spatial pattern separation. Science 325:210-213. CrossRef Medline

Deisseroth K, Singla S, Toda H, Monje M, Palmer TD, Malenka RC (2004) 
Excitation-neurogenesis coupling in adult neural stem/progenitor cells. Neuron 42:535-552. CrossRef Medline

Deng W, Aimone JB, Gage FH (2010) New neurons and new memories: how does adult hippocampal neurogenesis affect learning and memory? Nat Rev Neurosci 11:339-350. CrossRef Medline

Dupret D, Revest JM, Koehl M, Ichas F, De Giorgi F, Costet P, Abrous DN, Piazza PV (2008) Spatial relational memory requires hippocampal adult neurogenesis. PLoS One 3:e1959. CrossRef Medline

Hou SW, Wang YQ, Xu M, Shen DH, Wang JJ, Huang F, Yu Z, Sun FY (2008) Functional integration of newly generated neurons into striatum after cerebral ischemia in the adult rat brain. Stroke 39:2837-2844. CrossRef Medline

Imayoshi I, Sakamoto M, Ohtsuka T, Takao K, Miyakawa T, Yamaguchi M, Mori K, Ikeda T, Itohara S, Kageyama R (2008) Roles of continuous neurogenesis in the structural and functional integrity of the adult forebrain. Nat Neurosci 11:1153-1161. CrossRef Medline

Jia Y, An L, Wang RK (2010) Label-free and highly sensitive optical imaging of detailed microcirculation within meninges and cortex in mice with the cranium left intact. J Biomed Opt 15:030510. CrossRef Medline

Jin K, Wang X, Xie L, Mao XO, Greenberg DA (2010) Transgenic ablation of doublecortin-expressing cells suppresses adult neurogenesis and worsens stroke outcome in mice. Proc Natl Acad Sci U S A 107:7993-7998. CrossRef Medline

Kernie SG, Parent JM (2010) Forebrain neurogenesis after focal Ischemic and traumatic brain injury. Neurobiol Dis 37:267-274. CrossRef Medline

Kim ES, Kim GM, Lu X, Hsu CY, Xu XM (2002) Neural circuitry of the adult rat central nervous system after spinal cord injury: a study using fast blue and the Bartha strain of pseudorabies virus. J Neurotrauma 19:787-800. CrossRef Medline

Lee JW, Erskine MS (2000) Pseudorabies virus tracing of neural pathways between the uterine cervix and CNS: effects of survival time, estrogen treatment, rhizotomy, and pelvic nerve transection. J Comp Neurol 418: 484-503. CrossRef Medline

Leutgeb JK, Leutgeb S, Moser MB, Moser EI (2007) Pattern separation in the dentate gyrus and CA3 of the hippocampus. Science 315:961-966. CrossRef Medline

Lichtenwalner RJ, Parent JM (2006) Adult neurogenesis and the ischemic forebrain. J Cereb Blood Flow Metab 26:1-20. CrossRef Medline

Liu Z, Fan Y, Won SJ, Neumann M, Hu D, Zhou L, Weinstein PR, Liu J (2007) Chronic treatment with minocycline preserves adult new neurons and reduces functional impairment after focal cerebral ischemia. Stroke 38:146-152. CrossRef Medline

Matsumori Y, Hong SM, Fan Y, Kayama T, Hsu CY, Weinstein PR, Liu J (2006) Enriched environment and spatial learning enhance hippocampal neurogenesis and salvages ischemic penumbra after focal cerebral ischemia. Neurobiol Dis 22:187-198. CrossRef Medline

Neumann M, Wang Y, Kim S, Hong SM, Jeng L, Bilgen M, Liu J (2009) Assessing gait impairment following experimental traumatic brain injury in mice. J Neurosci Methods 176:34-44. CrossRef Medline

Pendlebury ST, Rothwell PM (2009a) Prevalence, incidence, and factors associated with pre-stroke and post-stroke dementia: a systematic review and meta-analysis. Lancet Neurol 8:1006-1018. CrossRef Medline

Pendlebury ST, Rothwell PM (2009b) Risk of recurrent stroke, other vascu- lar events and dementia after transient ischaemic attack and stroke. Cerebrovasc Dis 27 [Suppl 3]:1-11. CrossRef Medline

Raber J, Fan Y, Matsumori Y, Liu Z, Weinstein PR, Fike JR, Liu J (2004) Irradiation attenuates neurogenesis and exacerbates ischemia-induced deficits. Ann Neurol 55:381-389. CrossRef Medline

Rafuse VF, Soundararajan P, Leopold C, Robertson HA (2005) Neuroprotective properties of cultured neural progenitor cells are associated with the production of sonic hedgehog. Neuroscience 131:899-916. CrossRef Medline

Rinaman L, Levitt P, Card JP (2000) Progressive postnatal assembly of limbic-autonomic circuits revealed by central transneuronal transport of pseudorabies virus. J Neurosci 20:2731-2741. Medline

Sahay A, Scobie KN, Hill AS, O'Carroll CM, Kheirbek MA, Burghardt NS, Fenton AA, Dranovsky A, Hen R (2011) Increasing adult hippocampal neurogenesis is sufficient to improve pattern separation. Nature 472:466470. CrossRef Medline

Santra M, Liu XS, Santra S, Zhang J, Zhang RL, Zhang ZG, Chopp M (2006) Ectopic expression of doublecortin protects adult rat progenitor cells and human glioma cells from severe oxygen and glucose deprivation. Neuroscience 142:739-752. CrossRef Medline

Song J, Christian KM, Ming GL, Song H (2012) Modification of hippocampal circuitry by adult neurogenesis. Dev Neurobiol 72:10321043. CrossRef Medline

Sun H, Le T, Chang TT, Habib A, Wu S, Shen F, Young WL, Su H, Liu J (2011) AAV-mediated netrin-1 overexpression increases peri-infarct blood vessel density and improves motor function recovery after experimental stroke. Neurobiol Dis 44:73-83. CrossRef Medline

Toni N, Sultan S (2011) Synapse formation on adult-born hippocampal neurons. Eur J Neurosci 33:1062-1068. CrossRef Medline

Wang X, Mao X, Xie L, Sun F, Greenberg DA, Jin K (2012) Conditional depletion of neurogenesis inhibits long-term recovery after experimental stroke in mice. PLoS One 7:e38932. CrossRef Medline

Wang Y, Bontempi B, Hong SM, Mehta K, Weinstein PR, Abrams GM, Liu J (2008) A comprehensive analysis of gait impairment after experimental stroke and the therapeutic effect of environmental enrichment in rats. J Cereb Blood Flow Metab 28:1936-1950. CrossRef Medline

Wang Y, Bontempi B, Lesburguère E, Leinekugel X, Liu W, Weinstein PR, Liu J (2011a) Environmental enrichment preserves cortical inputs to the parahippocampal areas and reduces post stroke diaschisis. Am J Neuroprotect Neuroregen 3:66-76. CrossRef

Wang Y, Neumann M, Hansen K, Hong SM, Kim S, Noble-Haeusslein LJ, Liu J (2011b) Fluoxetine increases hippocampal neurogenesis and induces epigenetic factors but does not improve functional recovery after traumatic brain injury. J Neurotrauma 28:259-268. CrossRef Medline

Yu TS, Zhang G, Liebl DJ, Kernie SG (2008) Traumatic brain injuryinduced hippocampal neurogenesis requires activation of early nestinexpressing progenitors. J Neurosci 28:12901-12912. CrossRef Medline

Zhang R, Zhang Z, Wang L, Wang Y, Gousev A, Zhang L, Ho KL, Morshead C, Chopp M (2004) Activated neural stem cells contribute to strokeinduced neurogenesis and neuroblast migration toward the infarct boundary in adult rats. J Cereb Blood Flow Metab 24:441-448. CrossRef Medline 